\title{
O Uso da Aprendizagem Baseada em Equipes como Ferramenta Diagnóstica no Ensino-Aprendizagem de Química
}

\section{The Use of the Team-Based Learning as a Diagnostic Tool in the Chemistry Teaching-Learning}

\author{
Nairley Cardoso Sá Firmino ${ }^{\circledR}$ Brasil \\ Antônio Mateus Paiva Salustiano ${ }^{\circledR}$ Brasil \\ Diego Farias Firmino ${ }^{\circledR}$ Brasil \\ Luciana Rodrigues Leite ${ }^{\circledR}$ Brasil
}

A Aprendizagem Baseada em Equipes (ABE) é uma estratégia de ensino desenvolvida em etapas - pré-classe, garantia de preparo e aplicação de conceitos - que propõe romper com o tradicionalismo em sala de aula. Neste ensaio, recorreu-se a ABE como instrumento diagnóstico da aprendizagem de acadêmicos. Participaram do estudo, 127 estudantes do curso de Odontologia de um Centro Universitário cearense, matriculados no módulo Química. Eles estavam divididos em três turmas (duas regulares e uma especial, composta por estudantes repetentes) e participaram de duas etapas: preparo e garantia de preparo. Para sistematização das atividades, inicialmente, os estudantes foram orientados a realizar estudo domiciliar, com material didático fornecido previamente (pré-classe). A segunda etapa, constituída por testes individuais, coletivos e feedback do professor, teve os dados categorizados e analisados, em associação às narrativas dos acadêmicos. Houve crescimento na compreensão dos estudantes após o trabalho coletivo, as dificuldades foram maiores no conteúdo de forças intermoleculares e a turma especial expressou necessidade de apoio pedagógico direcionado. Concluise que o uso da $\mathrm{ABE}$ como ferramenta diagnóstica é viável, pois proporciona uma visão mais completa do processo educacional e auxilia no direcionamento do trabalho docente. Além disso, este ensaio agrega contributos à formação docente, pois, amplia as possibilidades de utilização da ABE no âmbito universitário e corrobora para que os professores a reconheçam como meio adjuvante do trabalho pedagógico, como um todo. Por fim, reitera-se o caráter inovador deste estudo, pois não foram identificadas, até então, publicações semelhantes na literatura da área.

Palavras-chave: Aprendizagem baseada em equipes; Ensino de Química; Ensino superior; Diagnóstico. 
Team-Based Learning (TBL) is a teaching strategy developed in phases - the pre-class, the guarantee of preparation, and the application of concepts - which proposes to break with traditionalism in the classroom. In this essay, TBL was used as a diagnostic tool for the learning of students. One hundred and twenty-seven students from the Dentistry course of a University Center in Ceará enrolled in the Chemistry module participated in this study. They were divided into three classes (two regular and a special one, composed of the repeaters students) and participated in two stages: preparation and guarantee of preparation. To systematize the activities, initially, the students were instructed to study at home, with the didactic material previously provided (pre-class). The second stage, consisting of individual, collective tests and feedback from the professor, had the data categorized and analyzed, in association with the narrative of the students. There was an improvement in the comprehension of the students after the collective work, the difficulties were higher in the content of intermolecular forces, and the special class expressed the need for directed pedagogical support. It was concluded that the use of TBL as a diagnostic mechanism is feasible, once it provides a complete visualization of the educational process and assists in directing the teaching work. Besides, this essay contributes to the professor training, once it increases the possibilities of using TBL at the university level and corroborates for the educators to recognize it as an adjunct of the pedagogical work, entirely. Finally, the innovative character of this study is reiterated, since similar publications were not, yet, identified in the literature of the area.

Keywords: Team-based learning; Chemistry teaching; Higher education; Diagnosis.

\section{Introdução}

A educação contemporânea é permeada por situações conflitantes e incertas. No tocante especificamente às instituições de ensino, observa-se que, de modo geral, há dificuldades na adequação à velocidade com que as mudanças se instauram na sociedade e predominância do uso de metodologias que mantém a centralidade do processo educativo na figura do professor. Essa realidade contribui para que se perpetue o reconhecimento dos discentes como sujeitos que "recebem" conhecimento e não como aqueles capazes de construir seu próprio saber.

O contexto ilustrado no parágrafo anterior faz parte da rotina pedagógica da maioria dos cursos de nível superior brasileiros. Por conseguinte, Masseto (2004, p. 198) aponta, dentre inúmeros aspectos que demandam modificação nessa realidade, a necessidade de "[...] substituição do papel do professor de ministrador de aulas e transmissor de informações para o papel de mediador pedagógico, desenvolvendo relação de parceria e corresponsabilidade com seus alunos, trabalhando em equipe [...]”. Ele destaca, ainda, que o modelo francês-napoleônico, que habita a origem dos cursos de Ensino Superior brasileiros, permanece fortemente enraizado na educação universitária contemporânea, de modo que as alterações posteriores não isentam a necessidade de mudanças. 
A tessitura deste trabalho foi edificada mediante a compreensão de que emerge a necessidade de inserção de transformações das circunstâncias atuais. Por conseguinte, as metodologias ativas são expressas como recursos que, certamente, contribuem para modificações na relação professor-aluno, aluno-aluno e aluno-conhecimento. Um dos objetivos das metodologias ativas reside em possibilitar que os estudantes se tornem protagonistas do processo educacional, em um fazer pedagógico no qual o docente atua como orientador, mediador e facilitador da aprendizagem, ou seja, seu papel não se restringe à exposição dos conteúdos e posterior avaliação do processo, expandindo-se para um trabalho mais consistente de formulação conjunta e contínua de conhecimentos.

$\mathrm{Na}$ literatura atual são identificadas diversas metodologias que compartilham dessa perspectiva, tais como a "Sala de aula invertida", cuja ideia principal reside no aluno estudar previamente o material indicado pelo professor, para que o encontro presencial seja a oportunidade de esclarecer dúvidas, desenvolver atividades e aprofundar conhecimentos (Bergmann \& Sams, 2016). Há também o "Problem-Based Learning PBL ou Aprendizagem Baseada em Problemas - ABP" que utiliza dificuldades da vida real para orientar as discussões e estudos, com vistas a contribuir para a motivação e concentração dos discentes na aprendizagem de conhecimentos conceituais, procedimentais e atitudinais (Ribeiro, 2008) - dentre outras.

Neste ensaio, foi utilizada especificamente a Aprendizagem Baseada em Equipes - ABE. Esta constitui uma metodologia ativa formada por um conjunto de práticas sequenciadas de ensino-aprendizagem (Krug et al., 2016) que requer a evocação de experiências e conhecimentos prévios dos alunos para ser efetivada e cuja aplicação ocorre em etapas: preparação individual (pré-classe); garantia de preparo e a aplicação dos conceitos (Bollela et al., 2014). A fase de preparo consiste em estudo individual (préclasse) no qual os estudantes são responsáveis por adquirir os próprios conhecimentos, por meio de materiais dirigidos pelo professor. A etapa seguinte ocorre em duas partes, um teste individual e um teste em grupo, sem consulta aos materiais didáticos, seguido de apelação e feedback do professor. A terceira etapa consiste na resolução de situaçõesproblema aplicadas pelo professor (Oliveira et al., 2018).

Fez-se uso desta estratégia de aprendizagem como suporte ao aprendizado de acadêmicos do curso de Odontologia de um Centro Universitário cearense, acerca dos conteúdos de Química. No referido curso, são necessários conhecimentos químicos para a compreensão dos processos de cárie e erosão dental, composição e propriedades dos materiais dentários, estrutura e ação de anestésicos, reações envolvidas nas revelações radiológicas, dentre outras especificidades. Portanto, no módulo de Química são estudados conteúdos básicos, como estrutura atômica, forças intermoleculares, propriedades dos elementos, dentre outros.

$\mathrm{O}$ interesse pelo desenvolvimento deste trabalho partiu do fato de serem corriqueiros, no contexto deste curso, relatos de alunos acerca de dificuldades de aprendizagem no referido módulo. Pensou-se, portanto, em desenvolver um trabalho que auxiliasse na identificação das principais dificuldades dos estudantes. A ABE foi 
utilizada neste processo por se presumir, de saída, que essa abordagem possibilitaria o alcance deste objetivo, além de, concomitantemente, dinamizar o trabalho pedagógico, em sala de aula, contribuindo para a autonomia dos acadêmicos e o estabelecimento de outras modalidades de aprendizagem.

É sabido que o gérmen da $\mathrm{ABE}$ reside no fato de se tratar de uma estratégia educacional construtivista que busca estimular, no estudante, o desenvolvimento de níveis avançados de aprendizagem (Michaelsen \& Sweet, 2008 citado em Nascimento \& Silva, 2019). Todavia, a experiência prática de utilização da ABE, no âmbito acadêmico, pelos autores desta investigação, os fez se questionarem e discutirem acerca das possibilidades de utilização desta estratégia educacional também como instrumento diagnóstico do aprendizado discente. Desse modo, o escrito sob relatório foi estruturado com amparo nesta pergunta norteadora: "Qual o potencial da $\mathrm{ABE}$ enquanto instrumento diagnóstico do aprendizado de Química por um grupo de estudantes de Odontologia?"

Por conseguinte, esta pesquisa foi estruturada mediante os objetivos de diagnosticar o aprendizado em Química de um grupo de acadêmicos cearenses, por meio da $\mathrm{ABE}$, assim como apresentar e analisar a possibilidade de utilização da $\mathrm{ABE}$ como instrumento diagnóstico do aprendizado discente. A análise desses dados foi utilizada para redirecionar estratégias de ensino, além de auxiliar na deteç̧ão de conteúdos que precisavam ser mais explorados. Reitera-se a noção de que o caráter inovador descansa no fato de a $\mathrm{ABE}$ ter sido utilizada como ferramenta diagnóstica, haja vista que esta perspectiva é pouco abordada na literatura da área, todavia, partiu-se da compreensão de que os resultados obtidos nas etapas da $\mathrm{ABE}$ fornecem uma visão mais ampla acerca da compreensão dos estudantes, pois permite que sejam analisados aspectos individuais e coletivos, por meio de informações objetivas e subjetivas coletadas no decorrer do processo.

\section{Metodologias Ativas e o Ensino de Química na Odontologia}

À extensão do tempo, as abstrações e a falta de contextualização, dentre outros fatores, concorrem para que os estudantes criem uma imagem negativa das disciplinas científicas. Com efeito, pesquisadores ressaltam há algum tempo a existência de uma crise na educação científica, visto que o ensino dessas disciplinas é estruturado em torno da memorização de fórmulas e conhecimentos que limitam o aprendizado (Santos et al., 2013). As dificuldades envolvidas na aprendizagem contribuem para que os conteúdos se tornem desinteressantes para os discentes, além disso, de acordo com Melo e Santos (2012), a natureza abstrata dos conceitos acarreta dificuldades na compreensão dos modelos científicos e promove o surgimento de concepções alternativas.

No tocante especificamente ao ensino de Química, observa-se que durante a educação básica grande parte dos estudantes não apreende conhecimentos específicos necessários para o desenvolvimento pessoal em outras etapas dos estudos. Belo et al. (2019) confirmam esta perspectiva ao apontarem que os altos índices de reprovação em alguns cursos da rede de Ensino Superior advêm das dificuldades de aprendizagem 
em Química oriundas do Ensino Médio. Compreende-se, portanto, que esses percalços precisam ser superados, pois o conhecimento químico é essencialmente necessário para uma sólida compreensão de processos biológicos, principalmente dirigidos a estudantes da área de saúde.

Para acadêmicos de Odontologia, o conhecimento químico está no centro de temas característicos do profissional odontólogo. Algumas das relações entre essas duas áreas do conhecimento foram demonstradas por Storgatto et al. (2017), ao explorarem as reações em equilíbrio químico que representam a desmineralização e mineralização do esmalte dental e o conceito de $\mathrm{pH}$, processos relacionados a cárie e erosão dental. Esses mesmos autores destacam que na radiologia, as revelações e fixações das imagens ocorrem por meio de reações de oxirredução. Além disso, há processos químicos envolvidos na utilização de substâncias que auxiliam na diminuição ou bloqueio da sensação dolorosa, contemplando inclusive a evolução desses processos no decurso do tempo. Essa relação também existe na caracterização dos materiais restauradores, a qual precisa da compreensão dos conceitos de ligações químicas e processos de polimerização, além do conhecimento acerca das propriedades dos elementos químicos constituintes destes materiais.

Considerando essa relação próxima entre a Química e a Odontologia, procura-se aperfeiçoar os processos de ensino e aprendizagem para fortalecer a compreensão dos processos biológicos, pelos estudantes. Uma vertente que contribui com essa realidade é a utilização de estratégias que incentivem uma posição ativa dos acadêmicos. As metodologias ativas tornam mais evidentes os papéis dos autores envolvidos no processo educativo - professores e alunos - ao ressignificarem a função do docente como facilitador da aprendizagem e do discente como corresponsável pelo seu desenvolvimento. De acordo com Macedo et al. (2018, p. 2), “[...] as metodologias ativas possuem uma concepção de educação crítico-reflexiva, com base em estímulos no processo de ensinoaprendizagem, resultando em um envolvimento por parte do educando na busca pelo conhecimento".

Estudos relatam experiências pedagógicas interessantes, como descrito por Chacon et al. (2016) que procederam uma análise sobre a articulação da Química com a Odontologia, utilizando mapas conceituais; e Storgatto et al., (2017) que trataram dessa relação pelo uso da contextualização. Por conseguinte, considerando que este estudo se dirige a uma experiência de utilização da ABE no ensino de Química para futuros odontólogos, trazendo, além da diversificação dos métodos de ensino, uma perspectiva de uso como diagnóstico da aprendizagem, a seguir destacam-se alguns aspectos acerca desta metodologia.

\section{Aprendizagem Baseada em Equipes}

A ABE foi criada em 1970 por Larry Michaelsen com o objetivo de melhorar a aprendizagem e desenvolver o trabalho coletivo (Oliveira et al., 2018). Nesse sentido, Sweet e Michaelsen (2012) citados em Nascimento e Silva (2019) consideram a ABE um 
sistema instrucional que amplia a participação intelectual e social dos alunos. Gullo et al. (2015) complementam essa perspectiva, considerando que a ABE desperta o interesse do estudante na busca de informação, tornando-o reponsável por sua aprendizagem e corresponsável pela aprendizagem dos colegas. Ademais, Silva et al. (2018) afirmam que a $\mathrm{ABE}$ fortalece o comprometimento no processo de aprendizagem, ressaltando os aspectos dirigidos a habilidades de comunicação e relações interpessoais, sendo observada uma evolução quanto ao exercício da dúvida.

A aplicação da ABE ocorre em etapas - "preparação individual" (pré-classe); "garantia de preparo" e "aplicação dos conceitos", de modo que as duas últimas ocorrem em sala de aula (Bollela et al., 2014). A fase de "preparação" exige do professor uma organização do material a ser disponibilizado e, do aluno, o compromisso de preparar-se individualmente. A "garantia de preparo" é dividida em subfases, nas quais o estudante é submetido, inicialmente, a testes individuais de múltipla escolha, sem direito a consulta aos materiais didáticos. A subfase seguinte consiste de testes coletivos, também sem direito a pesquisa, mas com discussões entre os integrantes dos grupos, permitindo trocas de experiências, conhecimentos e questionamentos que expressem dúvidas pertinentes. Com apoio nos diálogos, os integrantes de cada grupo devem eleger a alternativa que melhor representa o pensamento daquele grupo, constituído com as argumentações. Em seguida, é fornecido o gabarito dos grupos e ocorre o processo de apelação, no qual os integrantes empregam material de consulta nos argumentos. Essa etapa finaliza com o feedback do professor (Krug et al., 2016; Oliveira et al., 2018; Nascimento \& Silva, 2019). A fase de "aplicação dos conceitos" ocorre em um momento posterior, no qual são dispostas situações-problema envolvendo o conhecimento abordado na etapa da "garantia de preparo". De acordo com Nascimento e Silva (2019), embora as fases da ABE pareçam simples, sua condução exige habilidades para que as discussões se tornem envolventes e participativas.

A ABE é baseada no construtivismo, fundamentada na perspectiva de que o professor deve atuar como um facilitador da aprendizagem em um ambiente despido de autoritarismo e que privilegia a igualdade (Bollela et al., 2014). Nesse sentido, a ABE visa a promover o desenvolvimento de equipes de aprendizagem de alto desempenho e fornecer a elas oportunidades para se envolverem em tarefas de aprendizagem significativa (Krug et al., 2016). A vantagem na utilização da ABE está na possibilidade de trabalhar com grandes classes, em grupos de cinco a sete componentes aleatoriamente formados, evitando vínculos afetivos. Não há necessidade de uma grande quantidade de docentes nem múltiplas salas preparadas (Bollela et al., 2014).

Embora tenha sua origem nos cursos de administração, recorre-se a $\mathrm{ABE}$ com maior frequência em cursos da área de saúde. Estudos relatam o uso desta estratégia na educação médica (Krug et al., 2016; Oliveira et al., 2018). Além disso, Oliveira et al., (2016) publicaram um artigo no qual apresentam a ABE para uso no ensino de Física, em cursos de nível superior, e ressaltam a necessidade de mudanças nos modi operandi do ensino, com base no tradicionalismo, visando a uma diminuição da evasão desses 
cursos. No ensino de Química, uma experiência foi expressa por Walters (2013), na qual o autor afirma que $95 \%$ dos estudantes descreveram as tarefas de leitura como focadas e úteis e $81 \%$ disseram ter gostado do formato da ABE. Além disso, o autor relata que a $\mathrm{ABE}$ exigiu menos esforço que outras atividades para ser elaborada, as equipes se tornaram coesas e competitivas, a pressão dos colegas garantiu que os alunos chegassem às aulas com algum nível de preparação e houve sólida compreensão do assunto.

Como descrito anteriormente, a recorrência à $\mathrm{ABE}$ propicia inúmeros benefícios para a aprendizagem. Seu potencial para uso como via diagnóstica, entretanto, ainda não foi investigado. Por conseguinte, a proposta deste estudo reside em utilizar a $\mathrm{ABE}$, também, como instrumento auxiliar do professor na identificação de conteúdos nos quais existem deficiências de aprendizado por parte dos estudantes. É sabido que esse tipo de ação auxilia em um melhor direcionamento das estratégias de ensino, e a ABE, com arrimo em resultados individuais e coletivos, possibilita a visualização de um panorama do conhecimento discente acerca do conteúdo - este em estudo. Tal fato colabora com a ação pedagógica do professor, ao passo que a identificação dessa realidade facilita a estruturação de intervenções mais focadas nas necessidades dos estudantes. Sobre esses processos interventivos, Pinheiro e Rebouças (2018) destacam que eles não acontecem pela simples aplicação das avaliações diagnósticas, porquanto é preciso considerar sua funcionalidade e importância, pois por meio dos dados coletados pelos instrumentos diagnósticos são pensadas atividades e ações a realizar. E, no tocante às atividades diagnósticas, Luckesi (2005) ressalta que é preciso compreendê-las e realizá-las mediante o comprometimento com uma concepção pedagógica.

\section{Metodologia}

Esta pesquisa caracteriza-se como quali-quantitativa, quanto à sua abordagem, e exploratória, quanto aos seus objetivos, pois parte-se da compreensão de Minayo (2014) de que os conjuntos de dados qualitativos e quantitativos se complementam ao interagirem de modo dinâmico, contribuindo para o enriquecimento das análises, ao passo que o caráter exploratório está relacionado ao fato de esse tipo de estudo proporcionar familiaridade com o campo estudado, e ser aplicável em estudos iniciais para se obter uma visão geral acerca de determinados fatos (Gil, 2002).

Os sujeitos desta investigação foram 127 estudantes de Odontologia, mais especificamente os cursistas do módulo de Química, distribuídos em três turmas: duas regulares de primeiro semestre e outra formada apenas por alunos que já haviam reprovado a disciplina (turma especial). As turmas foram identificadas por A (49 alunos), B (47 alunos) e C (31 alunos), sendo a turma A composta pelos acadêmicos que estavam refazendo o módulo. 
A utilização da ABE como ferramenta diagnóstica, nessas turmas, ocorreu em duas etapas: preparação e garantia de preparo. Na etapa de preparação, foram realizados, sob a orientação do professor, estudos domiciliares de materiais a respeito dos conteúdos estrutura atômica, tabela periódica e ligações químicas. Na etapa seguinte, ocorreu a garantia de preparo, mediante aplicação do instrumento diagnóstico, seguindo os passos descritos na Figura 1, orientados por Bollela et al. (2014).

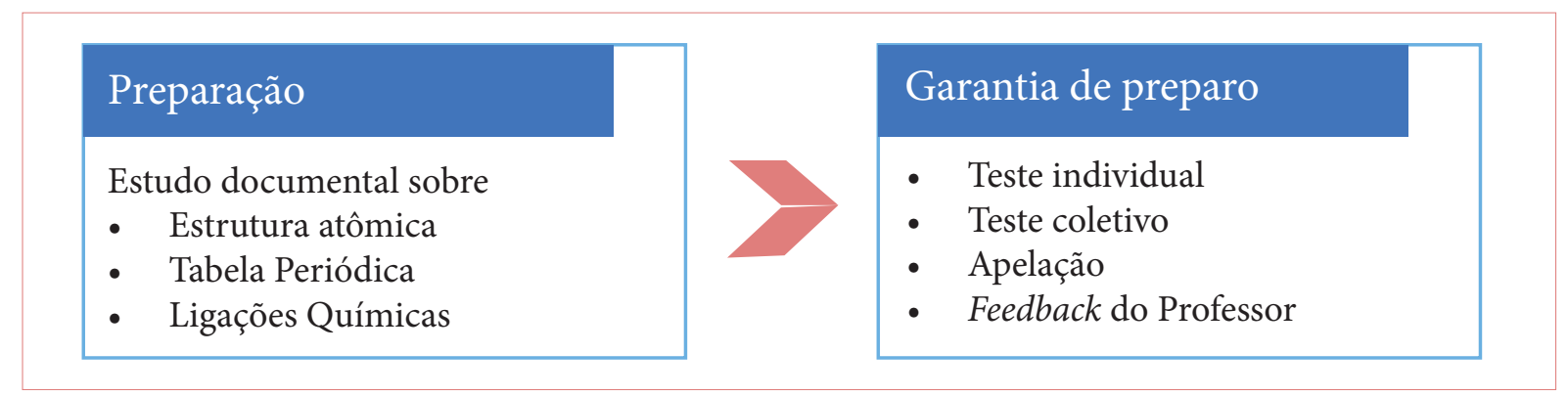

Figura 1. Representação esquemática das etapas da $\mathrm{ABE}$ desenvolvidas neste trabalho

A coleta de dados ocorreu de modo efetivo na etapa de garantia de preparo, que foi instrumentalizada da seguinte forma:

1. Os estudantes responderam o instrumental diagnóstico (Anexo 1), individualmente, sem consulta a materiais didáticos (teste individual).

2. Em seguida, foram formadas equipes de cinco ou seis pessoas e submetidas novamente às questões, mediante a possibilidade de realizarem discussões sem consulta aos materiais didáticos, e chegarem a um consenso na resposta (teste coletivo).

3. Mediados pelo professor, os grupos apresentaram suas respostas e, com a utilização do material didático, as apelações ocorreram entre os grupos juntamente com o feedback do professor (apelação e feedback).

A análise dos dados dos testes individuais e coletivos possibilitou diagnosticar o nível de aprendizagem de cada turma. Neste intento, o instrumental diagnóstico foi organizado com questões de múltipla escolha (itens), nas quais o gabarito correspondia à resposta correta e os distratores às opções incorretas. $\mathrm{Na}$ aplicação dos testes foram dadas as seguintes orientações aos estudantes: eles poderiam assinalar apenas uma opção e receber quatro pontos caso acertassem a resposta ou nenhum ponto caso assinalassem um distrator. Havia também a alternativa de assinalar duas opções. Se uma dessas opções fosse o gabarito, o grupo recebia dois pontos e se fossem distratores não receberiam nenhum.

A categorização dos resultados foi realizada considerando o conteúdo abordado em cada questão e os conhecimentos necessários para que o aluno descartasse opções incorretas ou marcasse o gabarito. Dessa maneira, de acordo com a escolha da alternativa, foram estabelecidas as seguintes categorias: Compreensão (C), Dúvidas (D) e Não 
Compreensão (NC), onde C se relacionava ao fato de os estudantes terem assinalado o gabarito; D quando eram marcadas duas opções, sendo uma delas o gabarito; NC, quando marcados um ou dois distratores (ver Figura 2).

\begin{tabular}{|c|c|c|c|}
\hline Alternativas & Condições & Pontuação & Categorização \\
\hline 1 & Gabarito & 4 & C \\
\hline 1 & Distrator & 0 & NC \\
\hline 2 & Gabarito e Distrator & 2 & D \\
\hline 2 & Distrator e Distrator & 0 & NC \\
\hline
\end{tabular}

Figura 2. Pontuação e categorização das respostas aos itens da $\mathrm{ABE}$

$\mathrm{Na}$ tabulação dos resultados, foi realizada a contagem dos pontos e os grupos foram ranqueados pela pontuação obtida. As respostas dos itens, tomadas por meio das etapas individuais e coletivas, foram tabuladas e os gráficos elaborados, utilizando o programa Microsoft Excel Office. Além disso, as discussões e reflexões desenvolvidas entre os grupos nas etapas de apelação e feedback foram descritas em um diário de bordo para posterior análise das narrativas. De acordo com Nunes et al. (2017), a análise de narrativas tem a proposta de ser um roteiro para pesquisadores de áreas distintas que necessitam interpretar dados por meio de falas e/ou diálogos.

Mostra-se precípuo acrescentar que os estudantes foram informados acerca dos objetivos e procedimentos do estudo, se dispuseram a participar sem nenhuma objeção e assinaram Termo de Consentimento Livre e Esclarecido concordando com a referida participação. Demais disso, seguindo os preceitos éticos de pesquisa, prezou-se pela privacidade dos sujeitos, protegendo suas identidades.

\section{Resultados e discussão}

Para a mostra dos resultados, inicialmente, são analisados os itens da $\mathrm{ABE}$, referentes aos testes aplicados, correlacionando os conteúdos dos enunciados das questões (Anexo 1) às opções. Na sequência, são expostos dados referentes ao diagnóstico da aprendizagem dos estudantes, considerando aspectos individuais e coletivos, além de serem apresentados e comparados os resultados de cada turma. E, por fim, analisam-se as narrativas dos estudantes quanto ao conteúdo de Química abordado.

Os itens do questionário diagnóstico foram analisados considerando a correlação entre o conteúdo principal contemplado nos enunciados desses itens e os conteúdos das opções, conforme disposto na Figura 3. Essa análise deu ensejo à criação de critérios de categorização relacionados com a resolubilidade do item e as possíveis dúvidas no processo de aprendizagem.

É perceptível o fato de que os itens privilegiavam de maneira correlacionada três grandes eixos dos conteúdos da Química: estrutura atômica, tabela periódica e ligações químicas. Segundo Pazinato (2016), esses conteúdos constituem tópicos fundamentais da Química, visto que cobrem a natureza íntima da matéria e suas transformações.

Os resultados da categorização realizada com esteio nos critérios de marcação 
das opções dos itens da $\mathrm{ABE}$ estão contidos na Figura 4. Esses dados correspondem à totalidade dos estudantes, participantes do estudo, e expressam, ainda, as relações entre os aspectos individuais e coletivos do trabalho desenvolvido em classe.

\begin{tabular}{|c|l|l|}
\hline Itens & Conteúdo principal & Correlações de conteúdos nas opções \\
\hline 01 & Estrutura atômica & $\begin{array}{l}\text { Propriedades periódicas } \\
\text { Forças intermoleculares }\end{array}$ \\
\hline 02 & Estrutura atômica & $\begin{array}{l}\text { Tabela e propriedades periódicas } \\
\text { Ligações químicas } \\
\text { Polaridade }\end{array}$ \\
\hline 03 & Forças intermoleculares & $\begin{array}{l}\text { Estrutura atômica e molecular } \\
\text { Ligações químicas } \\
\text { Polaridade }\end{array}$ \\
\hline 04 & Propriedades periódicas & $\begin{array}{l}\text { Estrutura atômica } \\
\text { Tabela periódica }\end{array}$ \\
\hline 05 & Estrutura atômica & Ligações químicas \\
\hline
\end{tabular}

Figura 3. Conteúdo principal e correlações presentes nos enunciados e nas opções dos itens da $\mathrm{ABE}$

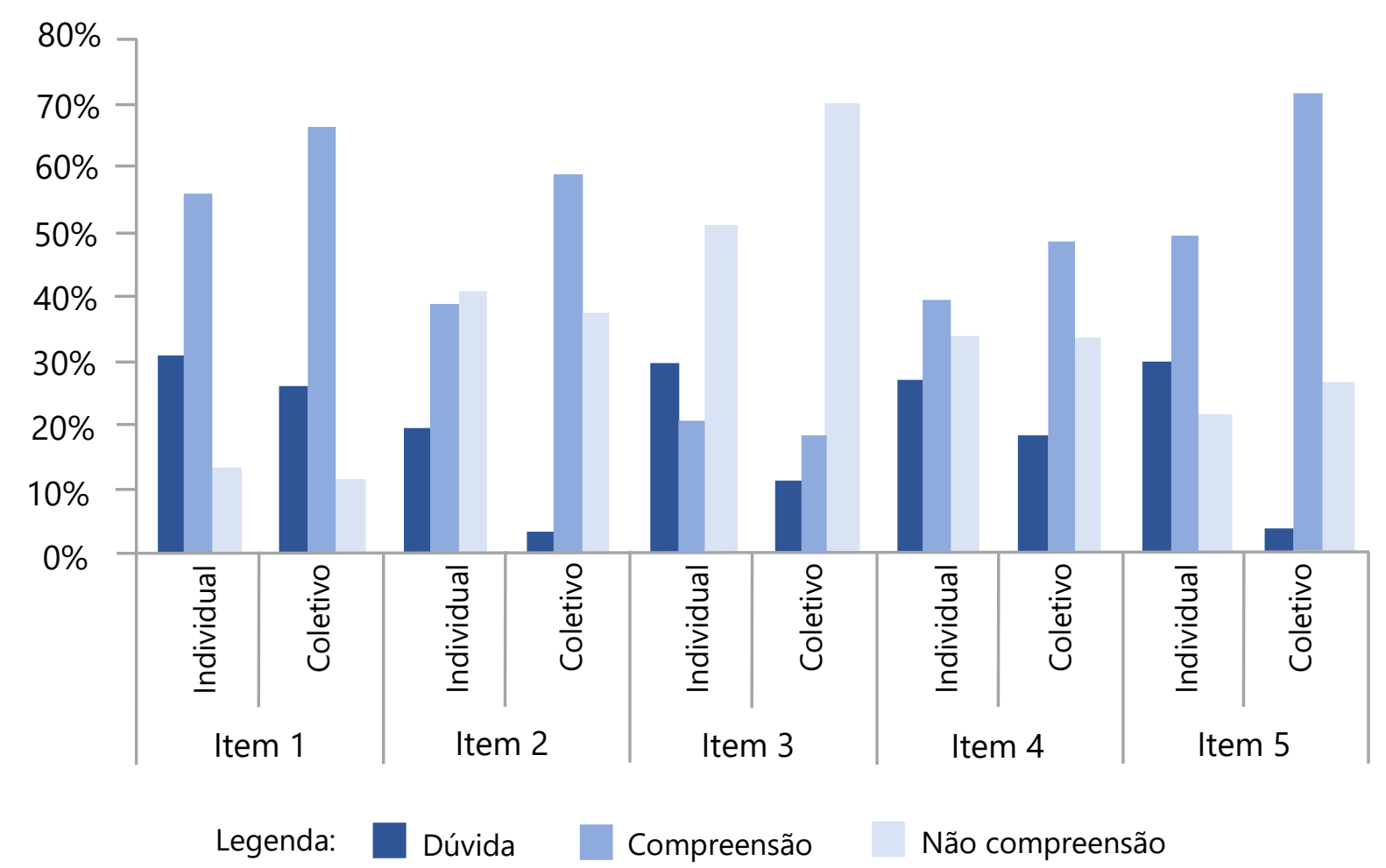

Figura 4. Resultados em percentual da categorização das respostas aos itens das ABE

De acordo com a Figura 4, considerando os dados individuais do item um, mais 
de $50 \%$ dos alunos marcaram o gabarito, enquadrando-se na categoria Compreensão (C), 31\% ficaram inseridos na categoria Dúvida (D) e aproximadamente $10 \%$ na categoria Não Compreensão (NC). Fazendo uma correlação com os dados dos grupos nesse mesmo item, percebeu-se que a discussão coletiva favoreceu C. No item dois, individualmente NC foi $41 \%$ e no trabalho coletivo reduziu para $37 \%$. O destaque nesse item, entretanto, é observado na relação entre $\mathrm{D}$ e C, pois, comparando os dados individuais e coletivos, ocorreram uma diminuição de cinco vezes de $\mathrm{D}$ e um aumento de $20 \%$ de C no sentido de individual para coletivo, ou seja, nesse item, o trabalho coletivo favoreceu o esclarecimento das dúvidas. Esses dois itens abordavam sobre o conteúdo estrutura atômica.

No item três, observou-se que nos dados coletivos NC aumentou para 70\%, enquanto $\mathrm{D}$ diminuiu, em comparação aos dados individuais. Considerando que a variação de $\mathrm{C}$ foi de apenas $1 \%$, percebeu-se que o trabalho coletivo, nesse caso, contribuiu para o crescimento de NC e que esse conteúdo precisa ser revisto, pois a maior parte dos alunos não o compreendeu ou tem dúvidas. O conteúdo principal do item três é forças intermoleculares, o qual está vinculado ao conceito de polaridade, estrutura das substâncias e o seu comportamento nas soluções. Esse conteúdo está diretamente relacionado às propriedades dos materiais, tais como temperatura, pontos de fusão e ebulição, solubilidade, densidade e viscosidade, além de permear diversos campos do conhecimento, a exemplo da área da saúde, na qual os estudantes precisam compreender as forças intermoleculares em contextos biológicos, os quais estão relacionados, por exemplo, à classificação de substâncias em hidrofóbicas e hidrofílicas, no processo de solvatação, trocas gasosas nos alvéolos, interações das fitas de DNA, entre outros.

Identificam-se pelo menos dois fatores que intervêm nas dificuldades de compreensão desse conteúdo, pelos estudantes. $O$ primeiro deles diz respeito às lacunas de aprendizagem advindas da educação básica, haja vista extensivo número de pesquisas ter revelado que o desenvolvimento do conteúdo em nível médio não atende à expectativa descrita pelos documentos oficiais, que regem a educação brasileira (Miranda et al., 2018). Por esse motivo, conceitos químicos da educação básica precisam ser reforçados no ensino superior.

O segundo fator diz respeito às concepções alternativas que os estudantes adquirem à extensão do tempo, pois conforme destacado por Miranda et al., (2017), a abstração do conteúdo de forças intermoleculares leva à utilização de modelos explicativos, os quais podem tornar o assunto complexo e gerar concepções alternativas aos modelos científicos. No âmbito desta investigação, foi possível identificar não somente haver essas concepções, mas também o fato de alguns desses erros conceituais serem repassados entre os estudantes. Isso contribui para que eles perpassem os níveis de ensino com algumas dificuldades de compreensão de conteúdos e ressalta a relevância do papel do professor no acompanhamento das discussões em grupo, no intuito de minimizar a disseminação dessas concepções errôneas acerca do conhecimento químico e possibilitar a promoção de uma evolução conceitual desses sujeitos.

No item quatro observou-se que o trabalho coletivo favoreceu C. Os dados 
mostraram que $\mathrm{D}$ diminuiu e NC permaneceu praticamente constante. $\mathrm{O}$ maior valor de $\mathrm{C}$, entretanto, ainda não representou 50\% dos estudantes nesse item. Os resultados relacionados ao item cinco indicam uma tendência semelhante a todos os outros itens na categoria $\mathrm{D}$, as dúvidas diminuíram no coletivo, entretanto verifica-se que o percentual de C aumentou em torno de $20 \%$ e NC também aumentou em menor proporção. Isso ratifica a compreensão de que o trabalho coletivo precisa ser acompanhado pelo professor, a fim de que a aprendizagem seja propagada e concepções errôneas sejam dissipadas. $\mathrm{O}$ item cinco trata de conceitos como número atômico, neutralidade elétrica, relação de massa e volume do núcleo e eletrosfera e camada de valência. Dessa maneira, identificouse que aproximadamente $25 \%$ dos estudantes precisam aprimorar-se nesse assunto.

De acordo com Medeiros (2013), o estudo da Tabela Periódica para o ensino das propriedades periódicas dos elementos é realizado por educadores, possivelmente da mesma maneira, desde o início do século XX. A classificação periódica dos elementos permite o estudo de propriedades físicas e químicas, mas o sucesso em sua aprendizagem é alcançado quando o conteúdo for abordado em associação com conceitos de átomo e com as teorias atômicas, que também são, assim como a periodicidade dos elementos, abstratos e distantes da realidade dos estudantes. Segundo Souza e Cardoso (2008), o ato de ensinar e aprender Química ou, em especial, periodicidade química requer processos de teorização, elaboração e reelaboração de modelos que possibilitem a interpretação e explicação dos resultados pelos estudantes.

Além da análise dos itens considerando a totalidade dos estudantes, foram verificados os resultados por turma, conforme reproduzido na Tabela 1.

Tabela 1. Categorização das respostas individuais e coletivas dos itens da ABE, por turmas

\begin{tabular}{|c|c|c|c|c|c|c|c|c|c|}
\hline \multirow{2}{*}{ Itens } & \multirow{2}{*}{ Categorias } & \multicolumn{4}{|c|}{ Individual } & \multicolumn{4}{|c|}{ Coletivo } \\
\hline & & Total & TA & TB & TC & Total & TA & TB & TC \\
\hline \multirow{3}{*}{01} & $\mathrm{D}$ & 39 & 21 & 11 & 7 & 7 & 2 & 1 & 4 \\
\hline & $\mathrm{C}$ & 71 & 24 & 27 & 20 & 17 & 7 & 7 & 3 \\
\hline & $\mathrm{NC}$ & 17 & 4 & 9 & 4 & 3 & 1 & 1 & 1 \\
\hline \multirow{3}{*}{02} & $\mathrm{D}$ & 25 & 8 & 10 & 7 & 1 & 1 & 0 & 0 \\
\hline & $\mathrm{C}$ & 49 & 5 & 29 & 15 & 16 & 1 & 9 & 6 \\
\hline & $\mathrm{NC}$ & 53 & 36 & 8 & 9 & 10 & 8 & 0 & 2 \\
\hline \multirow{3}{*}{03} & $\mathrm{D}$ & 37 & 11 & 16 & 10 & 3 & 1 & 1 & 1 \\
\hline & $\mathrm{C}$ & 26 & 9 & 10 & 7 & 5 & 1 & 3 & 1 \\
\hline & $\mathrm{NC}$ & 64 & 29 & 21 & 14 & 19 & 8 & 5 & 6 \\
\hline \multirow{3}{*}{04} & $\mathrm{D}$ & 34 & 16 & 9 & 9 & 5 & 4 & 1 & 0 \\
\hline & $\mathrm{C}$ & 50 & 15 & 23 & 12 & 13 & 4 & 6 & 3 \\
\hline & $\mathrm{NC}$ & 43 & 18 & 15 & 10 & 9 & 2 & 2 & 5 \\
\hline \multirow{3}{*}{05} & $\mathrm{D}$ & 38 & 18 & 13 & 7 & 1 & 1 & 0 & 0 \\
\hline & $\mathrm{C}$ & 62 & 13 & 27 & 22 & 19 & 3 & 8 & 8 \\
\hline & $\mathrm{D}$ & 39 & 21 & 11 & 7 & 7 & 2 & 1 & 4 \\
\hline
\end{tabular}

Legenda: TA - Turma A, TB - Turma B, TC - Turma C, C - Compreensão, D -Dúvidas, NC - Não compreensão 
Com esteio nos indicadores da Tabela 1, foi analisada a situação de cada turma. $\mathrm{Na}$ turma A, verificou-se que, nos resultados individuais do item dois, $68 \%$ de NC eram de estudantes da referida turma. Esse comportamento também foi observado nos itens três, quatro e cinco. Na turma B, nos itens um, dois, quatro e cinco, observou-se que os resultados de $\mathrm{C}$ foram superiores aos de $\mathrm{NC}$ nos dados individuais. Vale ressaltar os resultados do item dois coletivamente, no qual todos os grupos marcaram o gabarito. A turma C exibiu um comportamento semelhante ao da turma B.

As turmas B e C são regulares, ou seja, formada por estudantes admitidos ao curso. A turma A é constituída por alunos reprovados no módulo em semestres anteriores. De acordo com os dados da Tabela 1, identificou-se o fato de que as dificuldades dos estudantes da turma A persistiram de um semestre para o outro. Com efeito, se conclui que são necessárias estratégias de suporte ou de nivelamento para turmas desse tipo. A disponibilização de turmas especiais se caracteriza como uma ação de apoio aos estudantes com dificuldades de compreensão. Com suporte nos dados deste estudo, identificou-se a necessidade de complementação do apoio pedagógico, a ser fornecido por meio de nivelamentos, monitorias, materiais didáticos e um acompanhamento mais direcionado do docente. Nas turmas regulares, observou-se que existem dificuldades na compreensão dos conteúdos, mas que o próprio trabalho coletivo proporcionou um crescimento de C.

Um fator que merece discussão é o acompanhamento do trabalho coletivo, pois, nos resultados obtidos após a formação dos grupos, foram percebidos a diminuição de $\mathrm{C}$ e um crescimento de NC, principalmente na turma A nos itens dois, três e cinco. Algumas estratégias para a condução do trabalho coletivo podem ser utilizadas; sugere-se, por oportuno, que o professor se encarregue da formação dos grupos, na intenção de mesclar os estudantes com base em suas características. Segundo Johnson et al. (1999) citados em Teodoro et al. (2015), o docente deve distribuir os alunos em grupos, considerando a formação homogênea quando se intenta promover domínio de habilidades específicas e heterogênea para discutir a tarefa solicitada pelo professor. No último caso, ocorre um aprofundamento da compreensão e qualidade do raciocínio. Em estudo realizado por Fatareli et al. (2010), o professor, após organizar os grupos, distribuiu funções distintas aos integrantes, dando ensejo que todos os integrantes contribuíssem de maneira equilibrada na realização das atividades.

Ante o pressuposto, outra estratégia a ser adotada é proporcionar momentos de discussão entre alunos e professor, a fim de que as dúvidas sejam esclarecidas e assim evitar a propagação de erros conceituais. No sentido de propiciar a interação e discussão, o professor como facilitador da aprendizagem é um eixo basilar desse processo, para tanto deve usar de estratégias, durante a aplicação da $\mathrm{ABE}$, que possibilitem essa interlocução. De acordo com Oliveira et al. (2018), é tarefa do professor instigar a participação de todos os membros do grupo, devendo, então, acessá-los de modo igualitário, acompanhando o cerne das discussões. Além disso, esses autores sugerem que, na construção das atividades da $\mathrm{ABE}$, sejam elaboradas perguntas contendo duas opções corretas, sendo 
uma mais correta que a outra, pois isso estimula o estudante a buscar na literatura e desenvolver argumentos para a etapa de apelação.

Após os testes individuais e coletivos ocorreram as apelações entre os grupos juntamente com o feedback do professor. Nesta etapa, os grupos socializaram as respostas e nos casos de divergências foram realizadas discussões com direito a consultas aos materiais didáticos. Durante as discussões, identificaram-se os raciocínios que conduziram a erros conceituais, os quais foram explorados pelo professor no processo de intervenção. Eis algumas das narrativas:

Turma A: "Nós erramos porque esquecemos que o número atômico é o mesmo número de prótons" (Grupo 1); "Nós marcamos B e D porque ficamos em dúvida do que é mesmo interação dipolo-dipolo" (Grupo 2).

Turma B: "Naqueles quadradinhos ficam as setas para cima e para baixo, só não sei porque que é assim" (Grupo 3); "Não sei o que é um átomo no estado fundamental" (Grupo 4).

Turma C: "A energia de ionização do bromo não é maior que a do cloro porque o bromo vem depois do cloro na coluna" (Grupo 5). "As ligações de hidrogênio são as mais fortes, a gente se confundiu" (Grupo 6).

Com amparo nos discursos, verificou-se que os conceitos de número de prótons e as relações com outras partículas subatômicas não foram bem compreendidos. Esse fato foi expresso pelos Grupos 1 e 3 em seus relatos e também foi observado na utilização dos números de massa para fazer distribuição eletrônica. Com efeito, remata-se com a ideia de que parte dos alunos, apesar de se expressarem corretamente ao tratar do assunto de estrutura do átomo com núcleo e eletrosfera, ao aplicar em situações comuns em que se faz necessário o domínio desses conceitos, apresentam dúvidas. Sobre esse contexto, Camargo, Asquel e Oliveira (2018) enfatizam que o uso de modelos e abstrações está entre as principais dificuldades relacionadas ao ensino de modelos atômicos. Essa dificuldade, segundo eles, se dá pelo fato de o estudo sobre o átomo envolver o nível submicroscópico, ou seja, é algo que não se pode tocar, nem visualizar.

De tal maneira, é importante considerar, também, que a Química possui linguagem própria, utilizando-se de símbolos, gráficos e imagens que representam conceitos, e o conhecimento dessa linguagem é essencial para uma melhor compreensão dos processos e aplicação destes em reações químicas em meios biológicos, como é o caso dos estudantes de Odontologia. Considerando, entretanto, a fala do Grupo 3, percebeu-se que o uso do modelo de caixas na representação dos orbitais, para alguns estudantes, promoveu uma aprendizagem mecânica, ou seja, o aluno soube como fazer, mas não compreendeu o que aquilo significava. Nesse sentido, ressalta-se a importância da alfabetização científica, pois, segundo Sasse-Ron (2008) citado em Miranda et al. (2015), ao se alfabetizarem cientificamente os estudantes se desenvolvem intelectual e cognitivamente, facilitando a tomada de decisões e o pensamento crítico. Nesse processo são desenvolvidas habilidades, como: classificar informações, aperfeiçoar o raciocínio 
lógico, levantar e testar hipóteses e outras.

Com encosto na afirmação do Grupo 5, supôs-se que as propriedades periódicas e como estão dispostas na tabela periódica ficaram resumidas ao sentido das setas. Ou seja, os estudantes restringiram-se ao sentido das setas para responder às atividades, método geralmente empregado na educação básica. Desse modo, não foi possível concluir se houve aprendizado acerca do significado da energia de ionização ou se a resposta foi fruto da lembrança do sentido da seta em relação ao crescimento da energia de ionização ao longo da tabela periódica. Os autores Berbaum e Maldaner (2016) ressaltam a utilização das técnicas popularmente conhecidas como "decoreba", que proporcionam uma memorização temporária de alguns conceitos sem significação o que leva a uma aprendizagem na qual o estudante não consegue dar sentido ao conhecimento e elaborar um pensamento químico.

Nas afirmações dos Grupos 2 e 6, verificou-se que persistiam as dúvidas a respeito das interações intermoleculares. Considerando os dados do Gráfico 1, o referido conteúdo não foi compreendido por $70 \%$ dos estudantes e $11 \%$ permaneceram com dúvida, mesmo após o trabalho coletivo. Para a aprendizagem de forças intermoleculares, o estudante precisa compreender que quando há aproximação entre átomos, moléculas ou íons ocorrem dois fenômenos distintos, uma reação ou uma interação (Miranda et al., 2018). Em uma reação química, ocorre a conversão de uma ou mais substâncias em outras, consequência da formação ou ruptura de ligações químicas. Uma interação está relacionada com a atração ou repulsão entre moléculas ou íons entre si, sem que ocorra quebra ou formação de novas ligações químicas. A energia envolvida nesse processo é, em geral, bem menor que aquela envolvida em uma reação química.

Nesse caso, nota-se a necessidade de compreensão de vários conceitos envolvidos na aprendizagem de forças intermoleculares, tais como: reação química, ligações químicas, atração e repulsão, trocas de energia. É importante considerar que quando o estudante não domina esses conceitos, ocorre um reflexo na aplicação do conhecimento em diferentes contextos, e, que essa dificuldade na compreensão dos conteúdos químicos por parte dos alunos, de modo geral, deve-se ao fato de a Química ser estudada de maneira fragmentada, envolvendo conceitos abstratos e linguagem simbólica bastante específica (Camargo et al., 2018).

\section{Conclusões e Implicações}

Os resultados deste estudo mostraram a viabilidade do uso da $\mathrm{ABE}$ como ferramenta diagnóstica, ao possibilitar a identificação de conteúdos nos quais os estudantes possuíam maiores dificuldades e auxiliar na compreensão das relações nas aprendizagens individuais e coletivas. Restou identificado, o fato de que, de modo geral, as maiores dificuldades de compreensão dos estudantes residiram no conteúdo de forças intermoleculares. Tem-se como hipótese que a causa destas dificuldades descansa no elevado nível de abstração do referido conteúdo, nas lacunas de aprendizagem advindas da educação básica e em concepções alternativas que os estudantes adquirem no 
decorrer de seu percurso escolar, haja vista que concepções errôneas acerca do conteúdo foram identificadas por meio das narrativas coletadas. Tal fato ressalta a importância da constituição de um ambiente dialógico em sala de aula e a necessidade de o trabalho coletivo ser cuidadosamente conduzido para facilitar a aprendizagem e agregar elementos inerentes à formulação de conhecimentos.

Esses dados fortalecem a importância do professor como mediador nos processos de ensino e aprendizagem, pois o acompanhamento sistemático do docente, desde a formação dos grupos até o feedback após a fase de apelação, tende a permitir o esclarecimento de dúvidas. Além disso, reitera-se a ideia de que a utilização de resultados quantitativos e qualitativos proporcionou uma visão mais completa das turmas e, após esse processo de caracterização da aprendizagem, observou-se que a turma especial necessita de estratégias diferenciadas de ensino e ferramentas de apoio pedagógico que auxiliem os estudantes na superação das dificuldades encontradas no estudo de Química. É importante destacar que a detecção dessas deficiências tende a auxiliar o professor na elaboração de intervenções, pois com estas informações o trabalho será direcionado a fim de sanar dúvidas e facilitar o aprendizado.

Por conseguinte, mostra-se precípuo ressaltar o caráter inovador deste estudo, visto que as publicações envoltas nesse tema, dentre as quais estão inclusas Walters (2013), Oliveira et al. (2016) e Oliveira et al. (2018), tratam de aspectos relacionados à dinamização das estratégias de ensino, descrevem os passos para utilização do método, apresentam dados quantitativos que traduzem a aceitação dos estudantes acerca da metodologia e demonstram perspectivas de aplicação em outras áreas. A inovação, nesse caso, diz respeito especificamente ao fato de ter sido mostrado e discutido, no âmbito desta investigação, um modo de utilização da $\mathrm{ABE}$ como instrumento diagnóstico da aprendizagem discente. Não se tem conhecimento de que esta perspectiva tenha sido identificada na literatura da área até então, o que contribui para ampliar a conjunção de utilidades dessa abordagem metodológica, em sala de aula.

É sabido que outros estudos são desenvolvidos mediante a incumbência de apresentar novas maneiras de utilização da $\mathrm{ABE}$, em sala de aula. Alguns deles se coadunam com a proposta expressa neste artigo, a exemplo de Cunha et al. (2019), que experienciaram a $\mathrm{ABE}$ como estratégia de avaliação, como substitutiva da avaliação tradicional, em uma disciplina do curso de Medicina. Esses estudos agregam contributos ao contexto da formação de professores, haja vista que possibilitam o contato dos docentes com opções para inserção de novos recursos metodológicos em seu fazer-pedagógico e auxiliam na compreensão da gama de possibilidades intrínsecas ao uso da $\mathrm{ABE}$ no contexto escolar, seja como estratégia para promover motivação, engajamento, facilitar a aprendizagem, avaliar o conhecimento discente ou, ainda, diagnosticar conteúdos que precisam ser melhor compreendidos pelos estudantes.

Ainda no tocante à formação de professores, é importante considerar que estudos apontam a necessidade de uma mudança na educação, no sentido de reinventar os métodos de ensino e aprendizagem (Araújo, 2011 citado por Rech, 2016). Nesta 
perspectiva o docente deve ensinar os alunos a pensarem de maneira autônoma ao ponto de serem agentes transformadores de sua realidade (Freire, 2015). Para tanto, a execução de metodologias ativas, tais como a $\mathrm{ABE}$, necessita de formações continuadas específicas, para que o docente conduza adequadamente esse processo e, inclusive, o expanda de acordo com as necessidades dos estudantes.

Espera-se, portanto, que a divulgação desta experiência auxilie os docentes a perceberem e utilizarem a $\mathrm{ABE}$ não somente como recurso metodológico para diversificação de suas aulas, mas a reconhecê-la e utilizá-la como meio adjuvante do trabalho pedagógico como um todo, haja vista que os resultados desse estudo indicam que o uso da $\mathrm{ABE}$ proporciona uma visão mais completa do processo educativo e coadjuvam no direcionamento do trabalho docente, o que corrobora a viabilidade dessa abordagem como ferramenta diagnóstica.

É pertinente o destaque para as possibilidades de ampliação deste ensaio, haja vista que foi trabalhado somente com duas etapas da $\mathrm{ABE}$ - "preparo e garantia de preparo" Estudo posterior será capaz de vislumbrar a aplicação de todas as etapas, incluindo a "aplicação de conceitos" como um momento de intervenção a ser elaborado pelo docente, com base na identificação das necessidades individuais e coletivas dos acadêmicos, provenientes das etapas anteriores. Essa perspectiva, além de viabilizar a contextualização dos conceitos científicos, pode proporcionar a verificação de uma possível mudança conceitual dos estudantes e contribuir para a expansão do conjunto de possibilidades didático-metodológicas de inserção da $\mathrm{ABE}$ no contexto escolar. Além disso, outras estratégias de mensuração dos dados coletados e de organização das equipes poderão ser inseridas, a critério da criatividade e objetivos do professor.

\section{Agradecimentos}

Ao Centro Universitário INTA - UNINTA, Sobral, Ceará e aos estudantes, participantes do estudo.

\section{Referências}

Belo, T. N., Leite, L. B. P., \& Meotti, P. R. M. (2019). As dificuldades de aprendizagem de química: Um estudo feito com alunos da Universidade Federal do Amazonas. Scientia Naturalis, 1(3), 1-9.

Berbaum, L. C. M., \& Maldaner, O. A. (2016). Estratégias de ensino do conteúdo Tabela Periódica e sua relação com a aprendizagem conceitual em aulas de Química. In XVII Jornada de Extensão - Ciências Exatas e da Terra. UNIJUÍ.

Bergmann, J., \& Sams, A. (2016). Sala de aula invertida: Uma metodologia ativa de aprendizagem. LTC.

Bollela V. R., Senger M. H., Tourinho, F. S. V., \& Amaral E. (2014). Aprendizagem baseada em equipes: Da teoria à prática. Revista Medicina (Ribeirão Preto), 47(3), 293300. http://dx.doi.org/10.11606/issn.2176-7262.v47i3p293-300 
Camargo, L. C., Asquel, S. de S., \& Oliveira, B. R. M. (2018). Problematizando o ensino de modelos atômicos: Estudo das representações e o uso de um jogo didático. Revista ACTIO: Docências em Ciências, 3(3), 197-213.

Chacon, E. P., Carvalho, L. J., \& Ribeiro, C. M. R. (2016). A Odontologia como tema para o ensino de Química: Estudo e possibilidades por meio de mapas conceituais. Ensino, Saúde e Ambiente, 9(2), 45-62. http://dx.doi.org/10.22409/resa2016.v9i2.a21223

Cunha, C. R. O. B. J. da, Ramsdorf, F. B. M., \& Bragato, S. G. R. (2019). Utilização da Aprendizagem Baseada em Equipes como Método de Avaliação no Curso de Medicina. Revista Brasileira de Educação Médica, 43(2), 208-215. https://doi.org/10.1590/1981$52712015 v 43 n 2 r b 20180063$

Fatareli, E. F., Ferreira, L. N. de A., Ferreira, J. Q., \& Queiroz, S. L. (2010) Método cooperativo de aprendizagem Jigsaw no ensino de cinética química. Química Nova na Escola, 32(3), 161-168.

Gil, A. C. (2002). Como Elaborar Projetos de Pesquisa. 4. ed. Atlas.

Gullo, C., Ha, T. C., \& Cook, S. (2015). Twelve tips for facilitating team-based learning. Medical Teacher, 37(9), 819-824. http://dx.doi.org/10.3109/0142159X.2014.1001729

Krug, R. R., Vieira, M. S. M., Maciel, M. V. de A., Erdmann, T. R., Vieira, F. C. de F., Koch, M. C., \& Grosseman, S. (2016). O "Bê-Á-Bá" da Aprendizagem Baseada em Equipe. Revista Brasileira de Educação Médica, 40(4), 602-610. http://dx.doi.org/10.1590/1981$52712015 \mathrm{v} 40 \mathrm{n} 4 \mathrm{e} 00452015$

Luckesi, C. C. (2005). Avaliação da Aprendizagem Escolar: Estudos e proposições. Cortez. Macedo, K. D. S., Acosta, B. S., Silva, E. B., Souza, N. S., Beck, C. L. C., \& Silva, K. K. D. (2018). Metodologias ativas de aprendizagem: Caminhos possíveis para inovação no ensino em saúde. Anna Nery Revista de Enfermagem, 22(3), 1-9. http://dx.doi. org/10.1590/2177-9465-EAN-2017-0435

Masseto, M. (2004). Inovação na Educação Superior. Interface - Comunicação, Saúde, Educação, 8(14), 197-202. http://dx.doi.org/10.1590/S1414-32832004000100018

Medeiros, M. A. (2013). Avaliação do conhecimento sobre periodicidade química em uma turma de Química Geral do ensino a distância. Química Nova, 36(3), 474-479. http://dx.doi.org/10.1590/S0100-40422013000300019

Melo, M. R., \& Santos, A. O. (2012). Dificuldades dos licenciandos em química da UFS em entender e estabelecer modelos científicos para equilíbrio químico. In Anais do XVI Encontro Nacional de Ensino de Química. UFBA.

Minayo, M. C. S. (2014). Pesquisa social: Teoria, método e criatividade. 33. ed. Vozes.

Miranda, A. C. G., Braibante, M. E. F., \& Pazinato, M. S. (2017). Concepções alternativas sobre forças intermoleculares: Um estudo a partir das publicações da área de ensino. In Anais do X Congreso Internacional sobre Investigación en Didáctica de las Ciencias. 
Miranda, A. C. G., Braibante, M. E. F., \& Pazinato, M. S. (2018). Tendências do ensino e aprendizagem de forças intermoleculares a partir da análise de publicações em periódicos nacionais e internacionais. Revista Electrónica de Enseñanza de las Ciencias, $17(2), 394-419$.

Miranda, M. de S., Suar, R. de C., \& Marcondes, M. E. R. (2015). Promovendo a alfabetização científica por meio de ensino investigativo no ensino médio de Química: Contribuições para a formação inicial docente. Revista Ensaio, 17(3), 555-583. http:// dx.doi.org/10.1590/1983-21172015170302

Nascimento, F. G. do, \& Silva, G. R. (2019). Utilização do método Team-Based Learning (TBL) no processo de aprendizagem e desenvolvimento de habilidades na disciplina de custos. In Anais do XVI Congresso USP de Iniciação Científica em Contabilidade. USP.

Nunes, L. S., Paula, L. de, Bertolassi, T., \& Faria Neto, A. (2017) A análise de narrativas como instrumento para pesquisas qualitativas. Revista Ciências Exatas, 23(1), 9-17.

Oliveira, B. L., Lima, S. F., Rodrigues, L. S., \& Pereira Junior, G. A. (2018). TeamBased Learning como forma de Aprendizagem Colaborativa e Sala de Aula Invertida com centralidade nos estudantes no processo ensino aprendizagem. Revista Brasileira de Educação Médica, 42(4), 86-95. http://dx.doi.org/10.1590/1981$52712015 \mathrm{v} 42 \mathrm{n} 4 \mathrm{rb} 20180050$

Oliveira, T. E., Araújo, I. S. \& Veit, E. A. (2016). Aprendizagem Baseada em Equipes (Team-Based Learning): Um método ativo para o Ensino de Física. Caderno Brasileiro de Ensino de Física, 33(3), 962-986. http://dx.doi.org/10.5007/2175-7941.2016v33n3p962

Pazinato, M. S. (2016). Ligações Químicas: Investigação da construção do conhecimento no ensino médio. (Tese Doutorado). Universidade Federal de Santa Maria, Santa Maria.

Pinheiro, D. P., \& Rebouças, J. A. da S. M. (2018). A importância da avaliação diagnóstica no projeto de nivelamento matemático com discentes do ensino médio integrado. In $V$ Congresso Nacional de Educação - CONEDU. CECON.

Ribeiro, L. R. de C. (2008). Aprendizagem Baseada em Problemas - PBL: Uma experiência no Ensino Superior. Edufscar. http://dx.doi.org/10.7476/9788576002970

Santos, A. O., Silva, R. P., Andrade, D., \& Lima, J. P. M. (2013). Dificuldades e motivações de aprendizagem em Química de alunos do ensino médio investigadas em ações do (PIBID/UFS/Química). Scientia Plena, 9(7), 1-6.

Silva, S. C., Colle, F. E. S., Cavichioli, D., \& Souza, R. F. (2018). Aprendizado e desenvolvimento de habilidades no curso de Contabilidade: Uma pesquisa-ação com o método Team-Based Learning (TBL). Revista Enfoque: Reflexão Contábil, 37(3), 1-19. http://dx.doi.org/10.4025/enfoque.v37i3.39579

Souza, K. A. F. D., \& Cardoso, A. A. (2008). Aspectos macro e microscópicos do conceito de equilíbrio químico e de sua abordagem em sala de aula. Química Nova na Escola, 27, $51-56$. 
Storgatto, G. A., Braibante, M. E. F., \& Braibante, H. T. S. (2017). A Química na Odontologia. Química Nova na Escola. 39(1), 4-11. http://dx.doi.org/10.21577/01048899.20160054

Teodoro, D. L., Cabral, P. F. de O., \& Queiroz, S. L. (2015). Atividade cooperativa no formato Jigsaw: Um estudo no ensino superior de Química. ALEXANDRIA Revista de Educação em Ciência e Tecnologia, 8(1), 21-51. http://dx.doi.org/10.5007/19825153.2015v8n1p21

Walters, D. E. (2013). Team-Based Learning applied to a Medicinal Chemistry Course. Medical Principles and Practice, 22(1), 2-3. http://dx.doi.org/10.1159/000342819

\section{ANEXO 1 - Instrumental Diagnóstico}

Aprendizagem Baseada em Equipes

Conteúdo: Estrutura Atômica, Tabela Periódica e Ligações Químicas

01. (UFC) Quando átomos são ionizados, suas propriedades são alteradas drasticamente. Como exemplos, podemos relacionar um agregado de moléculas de bromo $\left(\mathrm{Br}_{2}\right)$ possui coloração vermelha. Já os íons brometos $\left(\mathrm{Br}^{-}\right)$, presentes nos cristais de brometo de sódio, $\mathrm{NaBr}$, são incolores; o sódio metálico $(\mathrm{Na})$ reage violentamente com água $\left(\mathrm{H}_{2} \mathrm{O}\right)$, enquanto os íons $\mathrm{Na}^{+}$são estáveis em meio aquoso $\left[\mathrm{Na}^{+}\left(\mathrm{H}_{2} \mathrm{O}\right) \mathrm{n}\right]$; moléculas de cloro $\left(\mathrm{Cl}_{2}\right)$ constituem um gás venenoso de coloração verde claro. Já os íons cloretos $\left(\mathrm{Cl}^{-}\right)$, presentes no sal de cozinha $(\mathrm{NaCl})$, são incolores e de baixíssima toxicidade. Assinale a alternativa correta.

A) Os raios iônicos dos ânions são menores do que os dos respectivos átomos neutros que os originam.

B) As propriedades dos átomos e de seus íons de origem são fortemente dependentes dos elétrons de valência.

C) As energias de ionizações dos íons são idênticas às dos respectivos átomos de origem.

D) Os íons sódio hidratados $\left[\mathrm{Na}^{+}(\mathrm{H} 2 \mathrm{O}) \mathrm{n}\right]$ constituem um exemplo típico de interações dipolo-dipolo.

E) A energia de ionização do bromo é maior do que a do cloro, posto que seu raio atômico é maior.

02. (UFC com modificações) Os dentes humanos são compostos essencialmente de carbonato de cálcio, $\mathrm{CaCO}_{3}$, e hidroxiapatita, $\left[\mathrm{Ca}_{10}\left(\mathrm{PO}_{4}\right)_{6}(\mathrm{OH})_{2}\right]$. Apesar de serem a composição do corpo humano de maior dureza, os dentes são atacados por ácidos, originando as cáries. Quando regularmente utilizadas, as pastas de dentes contendo íons fluoretos $\left(\mathrm{F}^{-}\right)$ocasionam a substituição dos íons hidroxilas da hidroxiapatita, formando a fluoroapatita $\left[\mathrm{Ca}_{10}\left(\mathrm{PO}_{4}\right)_{6} \mathrm{~F}_{2}\right]$. Essa substância apresenta maior dureza e é menos susceptível ao ataque ácido, tornando os dentes mais resistentes às cáries. (Dado: $\mathrm{F}^{9}$ )

A respeito do flúor, marque a alternativa correta:

A) Está localizado no primeiro período da tabela periódica. 
B) Forma ânion bivalente, visto que sua distribuição eletrônica termina em $\mathrm{p}^{6}$.

C) A partir da distribuição eletrônica do flúor, verifica-se que o número quântico secundário é 1 e o magnético é 0 .

D) Dentre os halogênios, o flúor possui a menor eletronegatividade, sendo, portanto, o mais reativo.

E) Os íons fluoretos participam da molécula da fluoroapatita, através de ligações covalentes apolares com os átomos de cálcio.

03. (UFC com modificações) A água apresenta-se no estado líquido, à temperatura ambiente e à pressão atmosférica, e entra em ebulição a uma temperatura que é cerca de $200{ }^{\circ} \mathrm{C}$ mais elevada do que a do ponto de ebulição previsto teoricamente, na ausência das ligações de hidrogênio. Com relação às ligações de hidrogênio, assinale a alternativa correta.

A) Ocorrem entre moléculas, onde o átomo de hidrogênio éligado covalentemente aos átomos mais eletropositivos, pelos seus pares de elétrons ligantes.

B) Originam-se da atração entre os átomos de hidrogênio de uma molécula de água, que têm carga parcial positiva, e o átomo de oxigênio de uma outra molécula, que tem carga parcial negativa.

C) Entre as interações intermoleculares, as ligações de hidrogênio são as mais fracas. Esse fator promove a tensão superficial, tornando a água capaz de formar gotas ou permitir que um inseto pouse em sua superfície.

D) Quanto maior for a eletronegatividade do átomo ligado ao hidrogênio na molécula, maior será a carga negativa no hidrogênio, e mais fraca será a interação com a extremidade positiva da outra molécula.

E) São interações muito mais fracas do que as forças de London, e desempenham papel fundamental na química dos seres vivos.

04. (UFPE com modificações) Considere os seguintes processos:

$$
\begin{aligned}
& \text { (a) } X(g) \longrightarrow X^{+}(g)+\text { e- (g) } \\
& \text { (b) } X^{+} \text {(g) } \longrightarrow X^{+2}(g)+\text { e- (g) } \\
& \text { (c) } Y(g)+\text { e- (g) } \longrightarrow \text { Y- (g) }
\end{aligned}
$$

Pode-se afirmar que:

I. A energia de ionização da equação "b" é maior que a da equação "a".

II. Se Y for o átomo de um halogênio, podemos dizer que o processo (c) libera energia.

III. A energia necessária para a realização do processo (b) é menor que a necessária para o processo (a).

IV. Os processos (a) e (b) exprimem, respectivamente, a primeira e segunda energias de ionização do átomo X. 
Está correto o que se afirma em:
A) I.
B) I e II.
C) II e III.
D) I, II e IV.
E) I, II, III e IV.

05. (UEMG com modificações) O desenvolvimento científico e tecnológico possibilitou a identificação de átomos dos elementos químicos naturais e também possibilitou a síntese de átomos de elementos químicos não encontrados na superfície da Terra. Sobre os conceitos relacionados à atomística, marque a alternativa correta.

A) O número de prótons de um átomo o caracteriza, ou seja, cada átomo possui um número atômico e isso o diferencia dos demais.

B) O átomo no estado fundamental, para manter a neutralidade elétrica, precisa possuir a mesma quantidade de prótons e nêutrons.

C) Um átomo pode adquirir carga elétrica tornando-se cátion ou ânion, para isso, precisa perder ou ganhar prótons na camada de valência.

D) A camada de valência de um átomo não influencia os processos envolvendo as ligações químicas: transferência e compartilhamento de elétrons.

E) O átomo é constituído por núcleo e eletrosfera. A eletrosfera ocupa um grande volume e, por isso, possui grande massa. O núcleo possui pequeno volume e com carga positiva. 


\section{Nairley Cardoso Sá Firmino}

() https://orcid.org/0000-0002-7684-5371

Centro Universitário INTA - UNINTA

Coordenadoria de Formação Docente e Educação a Distância (CODED)

Sobral, Ceará, Brasil

nairleysafirmino@gmail.com

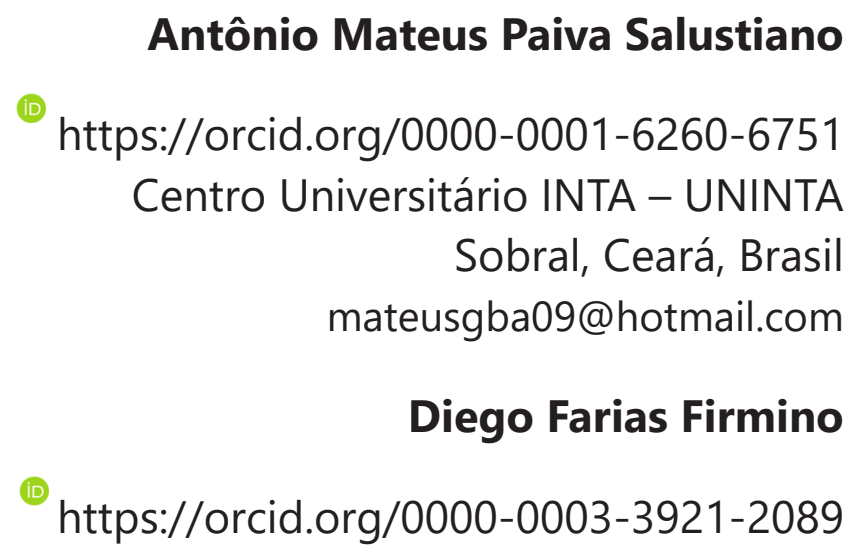

Coordenadoria de Formação Docente e Educação a Distância (CODED)

Sobral, Ceará, Brasil

diego.firmino12@gmail.com

Luciana Rodrigues Leite

${ }^{(1)}$ https://orcid.org/0000-0003-1915-6462

Universidade Estadual Vale do Acaraú

Centro de Ciências Exatas e Tecnológicas

Sobral, Ceará, Brasil

luciana_leite@uvanet.br

Submetido em 04 de maio de 2020

Aceito em 04 de setembro de 2020

Publicado em 15 de dezembro de 2020 